\title{
MODELLING OF STEROID ESTROGEN CONTAMINATION IN UK AND SOUTH AUSTRALIAN RIVERS PREDICTS MODEST INCREASES IN CONCENTRATIONS IN THE FUTURE
}

\begin{tabular}{|r|l|}
\hline Journal: & Environmental Science \& Technology \\
\hline Manuscript ID: & es-2012-051058.R1 \\
\hline Manuscript Type: & Article \\
\hline Complete List of Authors: & $\begin{array}{l}\text { Green, Christopher; Brunel University, Institute for the Environment } \\
\text { Williams, Richard; CEH Wallingford, Centre for Ecology \& Hydrology } \\
\text { Kanda, Rakesh; Severn Trent Laboratories Ltd, } \\
\text { Churchley, John; WatStech Ltd, } \\
\text { He, Ying; Environment Protection Authority, } \\
\text { Thomas, Shaun; Environment Protection Authority, } \\
\text { Goonan, Peter; Environment Protection Authority, } \\
\text { Kumar, Anu; CSIRO Land and Water, } \\
\text { Jobling, Susan; Brunel University, Institute for the Environment }\end{array}$ \\
\hline
\end{tabular}




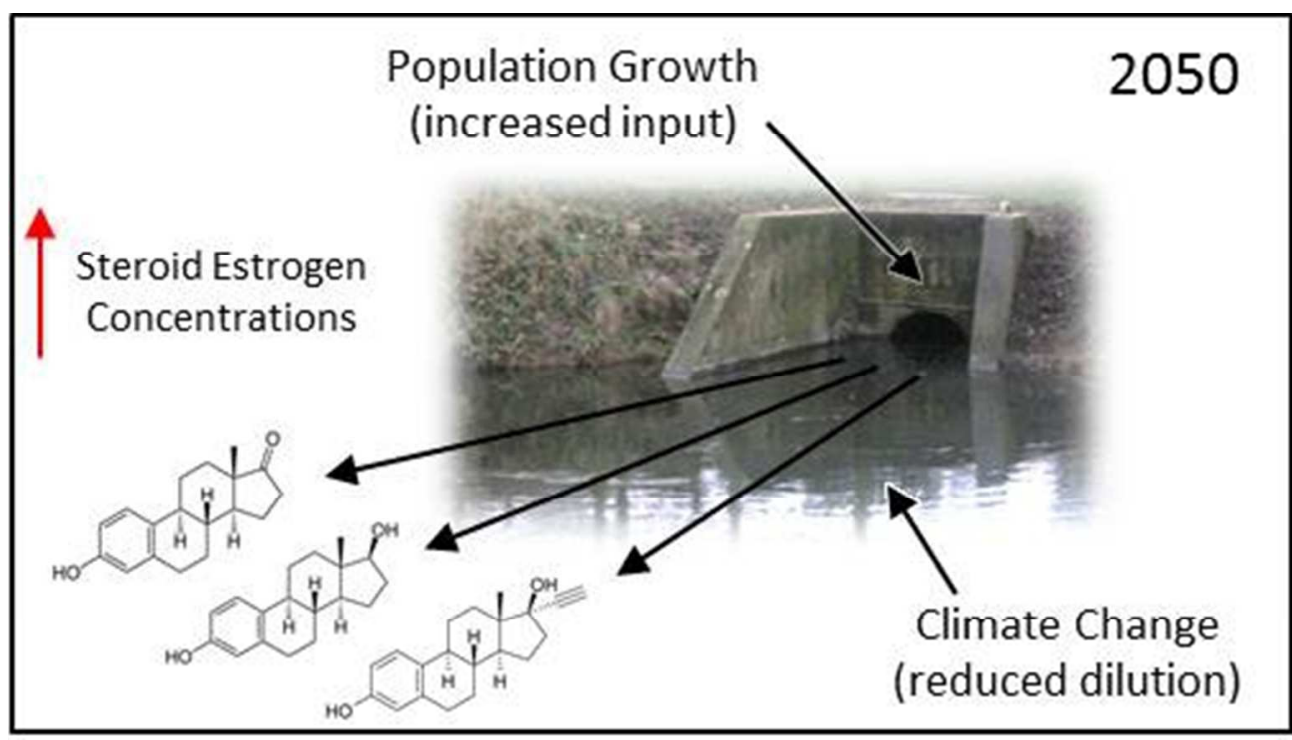

$86 \times 48 m m(150 \times 150$ DPI $)$ 


\title{
MODELLING OF STEROID ESTROGEN
}

\author{
CONTAMINATION IN UK AND SOUTH
}

\section{AUSTRALIAN RIVERS PREDICTS MODEST}

6 Christopher Green** ${ }^{1}$, Richard Williams ${ }^{2}$, Rakesh Kanda ${ }^{3}, J_{0 h n}$ Churchley $^{4}$, Ying He ${ }^{5}$, Shaun Thomas ${ }^{5}$,

\footnotetext{
${ }^{1}$ Institute for the Environment, Brunel University, Uxbridge, Middlesex, UB8 3PH, UK. ${ }^{2}$ Centre for Ecology and Hydrology, Wallingford, Oxfordshire, OX10 8BB, UK. ${ }^{3}$ Severn Trent Laboratories Ltd., Britten Road, Reading, Berkshire, RG2 OAU, UK. ${ }^{4}$ WatStech Ltd, Technology Centre, Wolverhampton Science Park, Wolverhampton, West Midlands, WV10 9RU, UK. ${ }^{5}$ Environment Protection Authority, 250 Victoria Square, Adelaide SA 5000, Australia. ${ }^{6} \mathrm{CSIRO}$ Land and Water, PMB 2, Glen Osmond, SA 5064, Australia
}

15 The prediction of risks posed by pharmaceuticals and personal care products in the aquatic environment now and in the future is one of the top 20 research questions regarding these contaminants following growing concern for their biological effects on fish and other animals. To this end it is important that areas experiencing the greatest risk are identified, particularly in countries experiencing water stress, where dilution of pollutants entering river networks is more limited. This study is the first to use 
hydrological models to estimate concentrations of pharmaceutical and natural steroid estrogens in a water stressed catchment in South Australia alongside a UK catchment and to forecast their concentrations in 2050 based on demographic and climate change predictions. The results show that despite their differing climates and demographics, modeled concentrations of steroid estrogens in effluents from Australian sewage treatment works and a receiving river were similar to those observed in the UK and Europe, exceeding the combined estradiol equivalent's predicted no effect concentration for feminization in wild fish. Furthermore, by 2050 a moderate increase in estrogenic contamination and the potential risk to wildlife was predicted with up to a two-fold rise in concentrations.

\section{KEYWORDS:}

Modeling; Steroid Estrogens; Climate Change; Population Growth; Endocrine Disruption; Fish

\section{INTRODUCTION}

In the last two decades the steroid estrogens, estrone (E1), 17ß-estradiol (E2) and the pharmaceutical $17 \alpha$-ethinylestradiol (EE2) have been identified as aquatic pollutants globally ${ }^{1-4}$. Originating from human excretion ${ }^{5}$ as natural steroids and from pharmaceutical use, they are continuously discharged into rivers via sewage treatment works' (STW) effluents, which can constitute up to $100 \%$ of river flow during dry periods ${ }^{6-8}$. As a result, contamination of river networks with steroid estrogens is widespread and there are extensive data to suggest they are the primary endocrine disruptors responsible for feminization of male fish ${ }^{9-11}$, particularly downstream of STW effluent discharges. Indeed, environmental concentrations of steroid estrogens can cause feminization effects in fish species maintained under laboratory conditions ${ }^{10,12-14}$, including the abnormal development of both ovarian and testicular tissue in the gonads. This intersex condition has been well characterized in the UK where it is widespread in the normally dioecius roach (Rutilus rutilus) ${ }^{15}$ inhabiting freshwater rivers ${ }^{6,711,16,17}$. Since reproductive performance of wild male fish has been negatively correlated with intersex severity, there 
has been cause for concern for wild fish populations ${ }^{18}$. In fact, during a whole lake experiment with regular dosing of EE2 at concentrations consistent with untreated effluent (mean 4.8-6.1 ng/L), an entire fish population collapsed ${ }^{19}$. This has led to the recent addition of E2 and EE2 to the list of "priority substances" by the European Commission in December 2012 as the first pharmaceuticals to be considered for regulation under the European Water Framework Directive ${ }^{20}$.

\section{In order to map the distribution of steroid estrogen contamination, pioneering hydrological modeling} methods have been used to predict concentrations of these chemicals in effluents and river networks, detecting "hot spots" of potentially at risk areas ${ }^{4,21-23}$. The results correlate well with measured effluent concentrations as well as the intersex incidence and severity in wild roach that inhabit the modeled river stretches ${ }^{11}$. Hydrological modeling with Low Flows 2000-WQX has been subsequently used in a risk assessment of the entire UK river network, predicting that around 39\% of the river stretches were at risk of inducing intersex in wild fish due to steroid estrogen contamination ${ }^{4}$. These modeling techniques have since been applied to investigate a range of mitigation options at $\mathrm{STWs}^{24}$ as well as the mixture effects of estrogens and xenoestrogens in a UK river catchment ${ }^{25}$. They have also been exported internationally for use in national risk assessments in the $\mathrm{USA}^{26}$ and Japan ${ }^{27}$, as well as for effluent modeling in $\mathrm{Chile}^{28}$.

Although the identification of at risk areas in the present day and the future is one of the top 20 research questions for pharmaceuticals and personal care products ${ }^{29}$, in many countries these types of risk assessments for steroid estrogens have not been completed since the hydrological models to enable this process have not been developed. In water stressed areas of the world, such models could be highly informative as lower water availability in these areas potentially reduces the dilution of these contaminants in the aquatic environment relative to other areas, increasing their concentrations and their risks to aquatic organisms. Moreover, the anticipated global population growth during this century alone $^{30}$, coupled with climate induced changes in precipitation ${ }^{31}$, provides an additional need to assess 
70 the consequences of changing water availability on future estrogen concentrations and their potential 71 impacts such that any mitigation options proposed are of an appropriate scale to be effective in the 72 longer term. To this end, this study uses hydrological modeling techniques to predict effluent and river 73 concentrations of steroid estrogens in moderately water stressed catchments in the UK and South 74 Australia. In addition, the models were modified to reflect population growth and climate-change 11

scenarios, producing the first future projections of steroid estrogen contamination and its potential impacts in UK and South Australian rivers by 2050 in an approach which can be used as a tool for risk management strategies involving large investments in improvements in waste water treatment.

\section{MATERIALS AND METHODS}

\section{Sites}

Four UK STWs (UK1-4) located in the Severn-Trent catchment, typical of the UK's urbanized environment, were compared with 12 STWs in South Australia (Table S1), representing a variety of rural and urban scenarios. Both catchments are considered to be moderately water stressed, since the demand and allocation of water is a high proportion of the total availability ${ }^{32-35}$. The river hydrology of the two catchments contrast with cooler, permanently flowing waters in the UK and warmer more ephemeral hydrology dominated by winter flow in South Australia.

\section{Modeling Natural Estrogens: Estrone (E1) and 17ß-Estradiol (E2)}

The model was based on an approach provided by Johnson and Williams, which has been applied to predict environmental concentrations of steroid estrogens in effluents in Europe ${ }^{23}$, as well as in hydrological models used for national risk assessments of endocrine disruption in rivers in the UK, Japan and the $\mathrm{USA}^{4,26,27}$. Our modified model provides a per capita load for E1 and E2 in $\mu \mathrm{g} / \mathrm{day}$ arriving at a STW, based on the proportions of different estrogen-excreting cohorts within a population. This was calculated as follows: 
95

$$
\mathrm{SE2}=0.5 \sum_{i=1}^{\mathrm{n}} f i(\mathrm{U} E 2)
$$

$$
\mathrm{S} E 1=\sum_{i=1}^{\mathrm{n}} f i(\mathrm{U} E 1)+0.5 \mathrm{SE} 2
$$

Where $S$ is the per capita load arriving at a STW $(\mu \mathrm{g} / \mathrm{d}), n$ is the number of cohorts and $\mathrm{U}$ is the total estrogen excreted in urine (in free, glucuronide and sulfate forms) and feces for each cohort percentage ( $f i)$ of the population. For E2, a factor of 0.5 is incorporated assuming that $50 \%$ will be degraded to E1 in transit through the sewerage system to a STW. The mean estrogen excretion of each cohort percentage is shown in Table 1 and is based on a literature review for the original model that focused on Caucasian omnivorous women ${ }^{23}$. Upper and lower excretion values were also used to provide a range

\begin{tabular}{|c|c|c|c|c|c|}
\hline \multirow[t]{2}{*}{ Cohort } & \multirow[t]{2}{*}{ Criteria } & \multicolumn{2}{|c|}{$\begin{array}{c}\text { Mean (range) excretion } \\
(\mu \mathrm{g} / \mathrm{d})\end{array}$} & \multicolumn{2}{|c|}{$\%$ of population } \\
\hline & & E2 & E1 & UK & Australia \\
\hline Menstrual females & Age $15-50$ & 3.2 & 11.7 & $23.5 \%$ & $24.2 \%$ \\
\hline & (minus pregnant women) & $(1.7-4.6)$ & $(7.5-15.4)$ & & \\
\hline Menopausal females & Age $>51$ & 1 & 1.8 & $16.1 \%$ & $13.7 \%$ \\
\hline & $\begin{array}{l}\text { (minus menopausal women on } \\
\text { HRT) }\end{array}$ & $(0-3.5)$ & $(0-5.7)$ & & \\
\hline $\begin{array}{l}\text { Menopausal females on } \\
\text { HRT }\end{array}$ & $\begin{array}{l}7.6 \% \text { UK and } 11.8 \% \text { Australian } \\
\text { menopausal females }(>51)\end{array}$ & $\begin{array}{c}56.1 \\
(51.5-61.5)\end{array}$ & $\begin{array}{c}28.4 \\
(24-33)\end{array}$ & $1.3 \%$ & $1.8 \%$ \\
\hline Pregnant Females & $\begin{array}{l}1 / 22 \text { UK and } 1 / 19 \text { Australian } \\
\text { menstrual females }\end{array}$ & $\begin{array}{c}393 \\
(340-445)\end{array}$ & $\begin{array}{c}550 \\
(432-668)\end{array}$ & $1.1 \%$ & $1.3 \%$ \\
\hline Males & Age $15-50$ & $\begin{array}{c}1.8 \\
(1.3-2.4)\end{array}$ & $\begin{array}{c}2.6 \\
(1.4-2.9)\end{array}$ & $39.0 \%$ & $39.2 \%$ \\
\hline
\end{tabular}
in the load arriving at a STW. A worked example can be found in the Supplementary Information.

Table 1. The population breakdown with the estrogen excreting cohorts by criteria and the composition of each census population: UK 2001 and Australia 2006. 
Cohort Criteria: The percentages of the populations made up by each cohort were based on age and determined from national census data, which was assumed to be relevant to local demographics. This utilized the national report for England and Wales (age by sex and resident type) from the 2001 census by the Office for National Statistics (ONS) and the Australian 2006 census (age by sex based on place of usual residence) from the Australian Bureau of Statistics (ABS). Pre-pubescent males and females were not incorporated since sex steroid production is low until puberty and their inclusion would have little effect on the final prediction ${ }^{23}$. As a result, the male cohort included those from age 15 onwards and menstrual females were assumed to be between 15 and 50 with menopausal females taken from the age of 51 onwards. The number of females on hormone replacement therapy (HRT) using E2 based pharmaceuticals was updated for our model where $11.8 \%$ of women over 50 were estimated to use HRT in Australia ${ }^{36}$ compared to $7.6 \%$ of women in the UK, calculated by combining population data from the 2001 census with data on HRT use in the UK in $2004^{37}$. These percentages were applied to the menopausal female cohort do determine the number of women on HRT, although it should be taken into account that HRT use has fluctuated in the last decade in both countries ${ }^{36,37}$. The number of pregnant females was estimated using the census data assuming that the number of live births (people aged 0) was representative of the number of pregnant females. Using this model, per capita loads of 3.4 (2.74.1) and $3.9(3.2-4.7) \mu \mathrm{g} / \mathrm{d}$ were produced for E2 in the UK and Australia respectively, as well as 14 $(10-18)$ and $16(12-20) \mu \mathrm{g} / \mathrm{d}$ for E1.

\section{Modeling Pharmaceuticals: 17a-Ethinylestradiol (EE2)}

The per capita load of EE2 was calculated based on the number of prescriptions in the UK and Australia, which were determined from the National Health Service's Prescriptions Cost Analysis (2009) for England ${ }^{38}$ and Wales ${ }^{39}$ and the Australian Statistics on Medicines $(2008)^{40}$, using a method from Runnalls et $\mathrm{al}^{41}$. About $17.4 \mathrm{~kg}$ of EE2 were prescribed in England and Wales in 2009 in comparison to $5.55 \mathrm{~kg}$ in Australia in 2008. With populations of 54,809,100 (mid 2009 estimate for England and Wales, ONS) and 22,000,000 (ABS estimation) for Australia and an excretion rate of $40 \%$ 
of the $\operatorname{dose}^{23}$, the per capita loads were estimated at 0.35 and $0.28 \mu \mathrm{g} / \mathrm{d}$ for the UK and Australia, respectively. The higher per capita load in the UK due to the higher prescription level of EE2 contrasted with that of E1 and E2, where the differences in population demographics resulted in a higher per capita load in Australia.

\section{Predicting Concentrations of Steroid Estrogens in STW Effluent}

Flow and population data for the STWs were provided by Severn Trent Water, UK and SA Water Corporation, Australia (Table S1). To predict effluent concentrations reflecting a 24-hour composite sample of effluent, the total load arriving at a STW (the per capita load $(\mu \mathrm{g} / \mathrm{d})$ of each estrogen multiplied by the population serviced) was divided by the total flow (L/day) through the STW (domestic plus non-domestic flow). Removal rates of $69 \%$ and $83 \%$ were incorporated for E1 and E2 respectively, based on a review of removal during the activated sludge process (ASP) ${ }^{42}$. The average, upper and lower per capita loads of E1 and E2 were all calculated based on the excretion range, whilst for EE2, average, upper and lower concentrations were produced in effluent using removal rates of $83 \%, 71.2 \%$ and $94.8 \%$ based on the average and standard deviation observed in the ASP review ${ }^{42}$. However, it should be recognized that in reality removal rates vary, even in a single STW, based on the treatment process and environmental conditions ${ }^{43}$.

\section{The Relevance to Real World Effluents}

To determine the relevance of modeled data to real world steroid estrogen concentrations in effluent, modeled concentrations were compared with measured data from UK2, where data from 19 24-hour composite samples of its activated sludge treated effluent were available from a previous study ${ }^{44}$. These were collected between July and December 2009 and analyzed by liquid chromatography-tandem mass spectroscopy (LC-MS/MS) as described previously ${ }^{45}$. LC-MS/MS measurements were compared with the average concentrations of the modeled estrogens, which were produced based on flow data provided by Severn Trent Water on the day of the composite sampling at UK2. 


\section{Predicting River Concentrations}

UK, Low Flows 2000-WQX: The Low Flows 2000 (LF2000) WQX (Water Quality eXtension) model (Wallingford Hydrosolutions) was used to predict concentrations of steroid estrogens in the River Erewash as described in William's et al $^{4}$. LF2000-WQX provided a map of interconnected river reaches, with artificial influences (e.g. abstractions and discharges) incorporated, where the magnitude and variability of flows at ungauged sites were estimated from runoff and generalized against gauged catchments. Steroid estrogens were assumed to enter the system continuously via the eight STWs on the Erewash including UK2 and 4, where the per capita load arriving at these STWs was based on the effluent model with serviced populations updated with new estimates from Severn Trent Water. The dry weather flows (DWF) through the STWs in the LF-2000 WQX model were updated in line with the population to maintain the per capita flow, whilst removal at each STW was based on the ASP review used in the effluent model ${ }^{42}$. The average concentrations of steroid estrogens on a given stretch were then determined based on an exponential decay model incorporating in-stream temperature dependent degradation (Table S2) ${ }^{46}$ and dilution based on the spatial variability in flow. Loss through absorption to sediment was not included since it is not a cause of significant removal ${ }^{47}$. Degradation of E2 to E1 was also incorporated based on 1 mol E2 degrading to 1 mol of E1.

\section{South Australia, Source Catchments:}

A point source hydrological model of the Onkaparinga River in South Australia was implemented and run in Source Catchments version 2.0.4 (eWater CRC) ${ }^{48,49}$ to predict steroid estrogen concentrations on a $16 \mathrm{~km}$ stretch downstream of the STW SA2. The river itself is vital to the water supply of the city of Adelaide, supplying the Mount Bold and Happy Valley Reservoirs. The model provided a node-link system representing a series of interconnected river stretches with artificial influences incorporated, where flow through the stretches (links) was calculated based on the SIMHYD rainfall-runoff model with laurenson flow routing ${ }^{49}$. Steroid estrogens were input as an inflow function at the node 
representing SA2 based on a time series of daily concentrations modeled from the daily flow rates from the STW in 2008 to simulate a continuous influx. Another inflow function was incorporated at a node downstream representing the inter-basin transfer of raw River Murray water from the Murray BridgeOnkaparinga pipeline by adding flow only as no STWs discharge within $500 \mathrm{~km}$ from this additional water source. The steroid estrogens were transported through the interconnected stretches from their source with their concentrations calculated on each stretch based on the available dilution from simulated flows and a simple exponential decay model using half-lives based on their typical degradation rates in UK rivers at $20^{\circ} \mathrm{C}$ water temperature ${ }^{46}$ (Table S2). However, this was not temperature dependent and it should be recognized that their degradation could differ in Australian rivers due to different environmental conditions. However, no data are available to support this possibility. Again, no loss to sediment was assumed and in contrast to LF2000-WQX, the conversion of E2 to E1 was not included, which could result in a small underestimation in concentrations of E1. In addition, the model does not incorporate the farm dam directly downstream of the STW which abstracts some water for irrigation, potentially affecting the concentrations of estrogens entering the main river stretch, below this point particularly during the summer months. However this could not be quantified.

\section{Risk Assessment of the Equivalent Estrogenic Activity}

Since estrogens exist in the environment in combination and act additively to induce similar biological effects, it is appropriate that a combined "toxic equivalent" is incorporated into any risk assessment. This is presented as the estradiol equivalent (EEQ) in $n g / L$, calculated based on their comparative estrogenic activity as $([\mathrm{EE} 2] / 0.1+[\mathrm{E} 2] / 1+[\mathrm{E} 1] / 3)$ with a PNEC of $1 \mathrm{ng} / \mathrm{L}^{50}$. To determine the risk to wild fish populations, the hydrological models of the rivers were used to map potential "hot spots" for estrogen concentrations: categorizing stretches as "no risk", "at risk" or "high risk", based on the EEQ $(<1,1-10 \text { and }>10 \mathrm{ng} / \mathrm{L} \text { EEQ respectively })^{4}$. This method of predicting the presence of "risk" stretches from the effluent model and LF2000-WQX has recently been compared 
1

2

28 $29^{223}$ 30

with LC-MS/MS analysis on the Erewash, where modeled and measured concentrations both produced the same risk categories for the river stretches based on the $\mathrm{EEQ}^{51}$.

\section{Predicting Estrogen Concentrations in 2050: The Effects of Population and Climate Change}

To determine how levels of steroid estrogens in effluents and rivers could change in the future, concentrations were modeled based on data relevant to 2050. These were then compared back to the predictions detailed above, produced from sources dating from 2001-2011, which are henceforth referred to as predictions for the present day. Data on population change was gathered from the "National Population Projections, 2010-based Projections" publication released in 2011 by the ONS, $\mathrm{UK}^{52}$ and "Population Projections Australia, 2006-2101" released in 2008 by the $\mathrm{ABS}^{53}$. Since projections were available for 2051 for both countries, these were assumed to be representative of 2050 and relevant to the local catchment areas. Three main projections were used for each country based on demographic assumptions of future fertility, mortality and migration to produce different scenarios for population change. These included a principal projection (B) which assumed that current trends in these demographic assumptions would prevail in the future and high (A) and low (C) population projections to provide a range.

Since the data were available on an age by sex basis, new per capita loads for E1 and E2 were produced based on new estrogen excreting cohorts relevant to 2050 to incorporate the change in population composition (Table S3). Additionally, the per capita load of EE2 was changed in line with the proportion of menstrual females: the users of the contraceptive pill. The effluent concentrations at the STWs under each population projection relevant to 2050 were then calculated using the new per capita loads and assuming that the populations serviced changed in line with the population change from 2011-2051 (Tables S4 and 5). No changes were made to the DWF at the STWs, which remained at present day levels to provide a worst case scenario which assumed that no additional water was available for dilution. 
The river models used the data above at the STW inflows and were modified to incorporate predicted climate-induced changes to flow. In the UK, the flow on the Erewash in LF2000-WQX was modified with flow data from the UK Climate Projections (UKCP09) simulation afgcx, which is one of 11 physically plausible simulations relevant to a medium emissions scenario in the $\mathrm{UK}^{54}$. As a result the flows were on average 5.2\% lower than the 2009 model on each stretch. Estrogen concentrations along the river were again calculated with inflow from the STWs based on the updated population data relevant to each projection. Again, no changes were made to the DWF. Due to the lack of available data for South Australia, the Source Catchments model was modified by reducing flow on each stretch by $17.5 \%$ from its 2008 level to provide a medium range climate model. This was based on a $15-25 \%$ reduction in annual stream flow for the Murray River projected for 2050 using two medium sensitivity climate scenarios, A1 and B1, from the Special Report on Emissions Scenarios ${ }^{55}$.

\title{
Statistical Analyses
}

Predicted estrogen concentrations based on the average per capita load from STW effluents in the UK and South Australia were compared by two sample $t$-test assuming equal variances. Variation in concentrations between STWs was assessed by Kruskal-Wallis one-way analysis of variance (ANOVA).

Statistical significance was taken as $\mathrm{P}<0.05$.

\author{
RESULTS AND DISCUSSION \\ Predicted Concentrations of Estrogens in STW Effluents
}




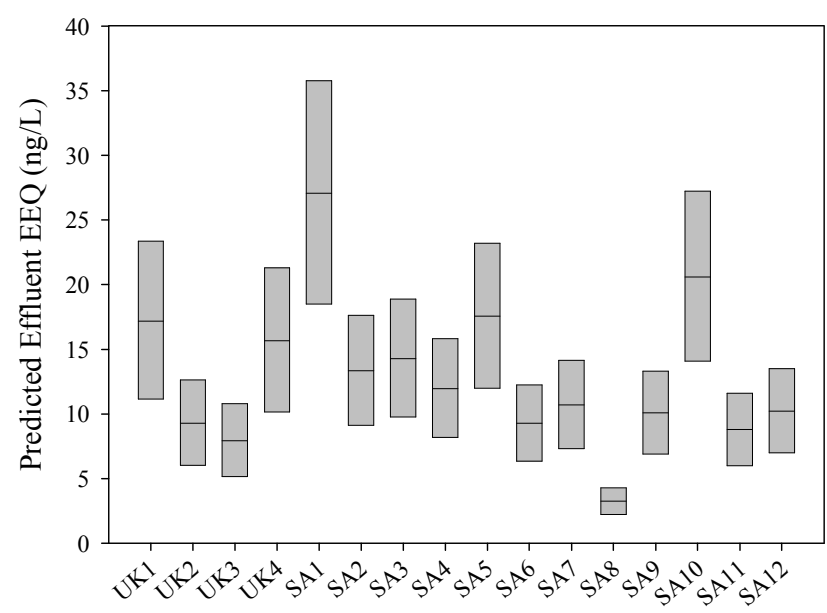

Figure 1. The predicted EEQs of effluents from UK and South Australia STWs predicted based on 19

the average, upper and lower per capita loads of the steroid estrogens. Boxes represent the EEQ based on the median (solid line), $5^{\text {th }}$ and $95^{\text {th }}$ percentiles.

Using the estrogen model the total load arriving at Australian STWs in the present day was found to be lower than the UK due to the lower population serviced on average. However, the lower flow through Australian STWs produced a similar dilution factor (the per capita flow) to the UK (Table S1). As a result, the predicted concentrations of E1, E2, EE2 (Figures S1) and the EEQ were similar in both the UK and South Australian effluents (Figure 1), corresponding with the overlapping measured data range from the two countries and a review of effluents globally ${ }^{56}$. Significant variation in concentrations of E1, E2 and the EEQ also originated from the differences in per capita flow, demonstrating the importance of dilution in predicting estrogen concentrations. No significant variation in concentrations of EE2 was observed due to the range in concentrations at each STW caused by the inclusion of the upper and lower removal rates.

\section{The Relevance to Real World Effluents}

In previous studies predictive modeling has been shown to produce environmentally relevant estimations for $\mathrm{STWs}^{43}$. On a national scale the range of concentrations predicted by this study for both 
3278

4

5279

6

7280

9

10281

11

12

13

14

15

16

17

18

19

20

21

22

23

24

25

26

27

28

29

30

31

32

33

34

35

36

37

38

39

40

41

42

43

44

45

46

47282

48

$49_{283}$

50

51

$52^{284}$

53

54285

55

${ }_{57}^{56} 286$

58

59

60

the UK and South Australia were within the range of measured concentrations from 43 UK STWs ${ }^{57}$ and over 70 STWs in Australia, ${ }^{3,56,58-64}$ (Table S6). The exception to this was SA1, which exceeded the 54 $\mathrm{ng} / \mathrm{L}$ reported maximum observed concentration of E1 in Australia ${ }^{63}$. Although the range provided by the assessment of 70 effluents is relatively extensive, it only represents a small proportion of Australian STWs and it is plausible that higher concentrations could occasionally occur in some of the older STWs.
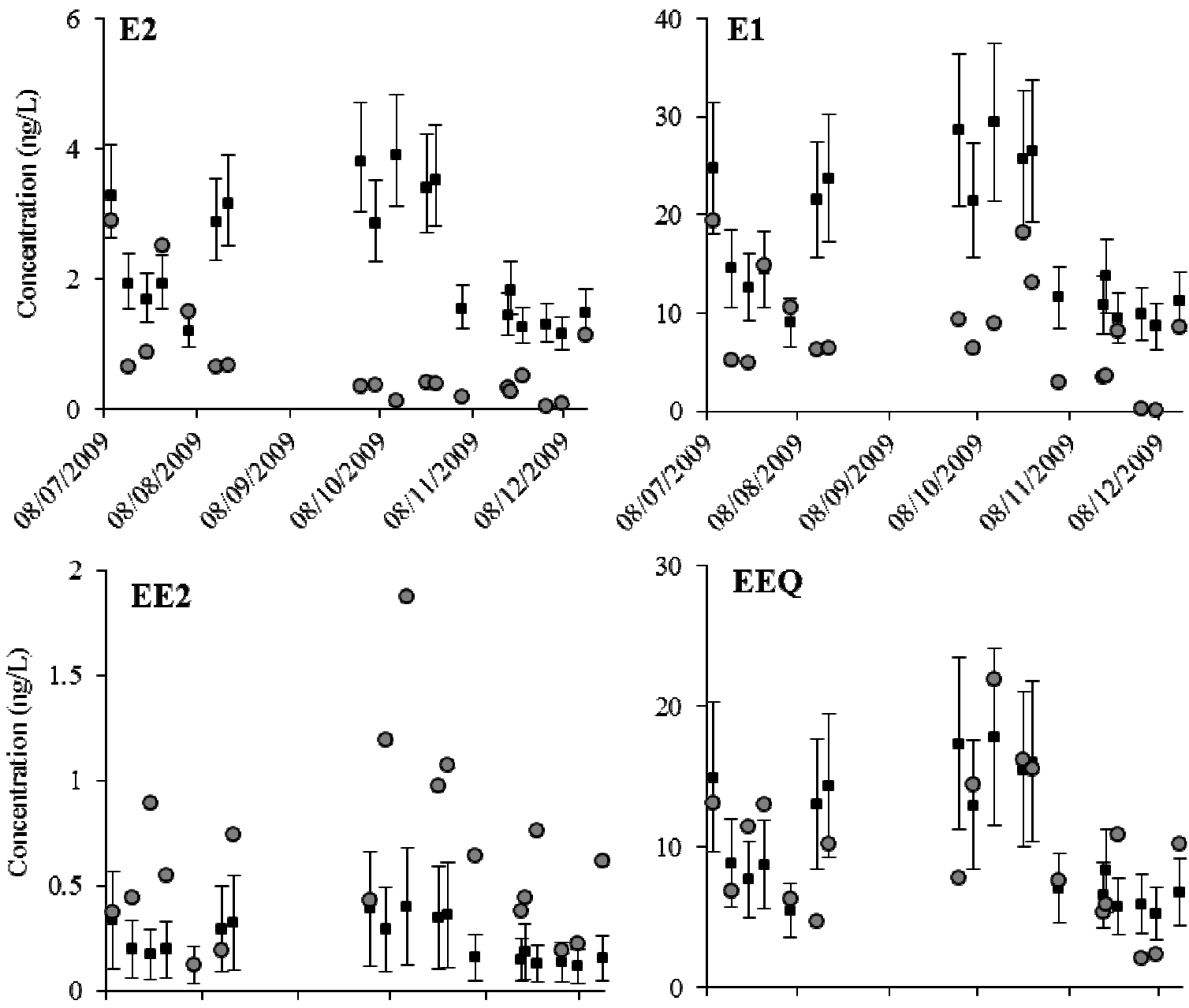

307 EEQ
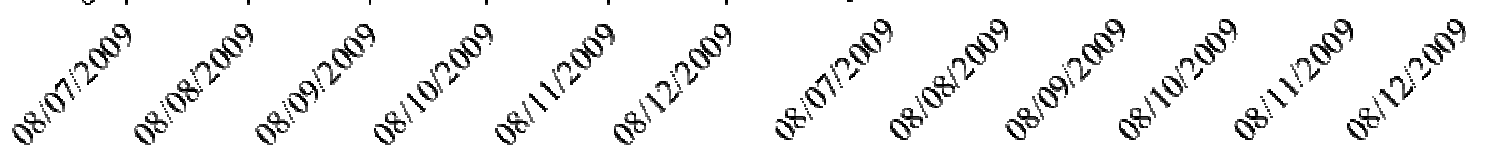

Figure 2. A comparison of modeled and measured estrogen concentrations with the EEQ (ng/L) in effluent from UK2 over 19 sampling points from July to December 2009. A data gap exists between 27.8.11 and 21.9.09 due to the lack of available flow data to produce modeled concentrations. Dots represent the analytical measurement at each sampling point. Square points show the corresponding 
average modeled concentration, with error bars showing the range based on the upper and lower per capita loads.

In a review of comparisons between modeled and measured data, predicted concentrations of pollutants in effluent were routinely predicted within a factor of 5 of the measured values ${ }^{43}$. At UK2, when modeled concentrations were compared with measured concentrations from effluent samples collected between July and December 2009, clear temporal variation was observed in both datasets (Figure 2). The differences between measured and modeled concentrations at each sampling point also varied where predictions for E1 and E2 both tended to be higher than the measured by a factor of 0.9-54 (median 3.1) and 0.8-33 (median 4.7) respectively. However, modeled concentrations of EE2 tended to be lower than the measured by a factor of 0.2-1.5 (median 0.4 ). These deviations in opposing directions produced a smaller deviation in the modeled EEQ, which was generally higher than the measured by a factor of 0.5-3.0 (median 1.0). However, it is important to note that every STW is unique and that the deviations in the datasets observed at UK2 may be very different in another STW.

A majority of modeled data points were within the measured range for the STW for each steroid estrogen, demonstrating that the model can be considered to produce environmentally relevant preliminary estimates for steroid estrogens applicable to a specific STW effluent. However, it is clear that changes in flow alone cannot explain the fluctuations in the measured data. This is likely to be due to the additional impact of changing estrogen input and removal, which fluctuate naturally instead of remaining constant as the model assumes. Significant changes in input are unlikely to be a common occurrence, so fluctuating removal is likely to be a major cause of sudden changes in the deviation factor between the modeled and measured data. Removal rates not only vary between STWs dependent on the treatment process but will also vary day to day within a single STW dependent on the effects of environmental conditions and flow on biodegradation ${ }^{65}$. Indeed, at UK2 removal rates are reported to be higher than those assumed in the model for E1 and E2 (95 and 98\% respectively) and lower for EE2 
$(32 \%)^{66}$. When these measured removal values were input into the model, the deviation factor lowered to $0.2-9.4$ (median 0.53) for E1, 0.1-3.8 (median 0.55) for E2, 0.7-6.1 (median 1.53) for EE2 and 0.5-3.0 (median 1.1) for the EEQ. In addition, with these new removal rates incorporated, all modeled data was within the measured range, demonstrating that the model can benefit from more specific data from a given STW. This also implies that river models will be more accurate with up to date removal data, although due to the impact of dilution, modeled estrogen concentrations based on the removal rates that overestimated concentrations by up to 10 fold still predicted concentrations within the same risk category as measured data ${ }^{51}$.

\section{Predicted River Concentrations in the Present Day and Risk Assessment for Endocrine Disruption}

\section{in Fish}

LF2000-WQX and Source Catchments were used in the UK and South Australia to identify potential hot spots of "at risk" areas for endocrine disruption in fish based on predicted concentrations of steroid estrogens in the present day. On the River Erewash, UK, in agreement with data from the Johnson and Williams model ${ }^{51}$ almost the entire river was categorized as "at risk" of endocrine disruption in wild fish (Figure 3), with an average EEQ of $2(0-7) \mathrm{ng} / \mathrm{L}$ along the entire river. This resulted from the assumption of constant influx of steroid estrogens from the eight STWs along the river which maintained the EEQ above $1 \mathrm{ng} / \mathrm{L}$. On the Onkaparinga River in South Australia, concentrations were also predicted to exceed the $1 \mathrm{ng} / \mathrm{L}$ EEQ PNEC (Figure 3) downstream of SA2. Around $9 \mathrm{~km}$ of the river was categorized as "at risk," with concentrations decreasing with the distance downstream due to degradation and dilution from tributaries, eventually dropping below the PNEC upstream of the Mount Bold reservoir. An average EEQ of $3(0.4-9) \mathrm{ng} / \mathrm{L}$ was predicted over these river stretches and individual steroid estrogen concentrations were comparable with those measured at five river sites in Queensland at effluent outfalls and $1 \mathrm{~km}$ downstream of STWs ${ }^{60}$. They also compared with concentrations measured globally ${ }^{67}$. 


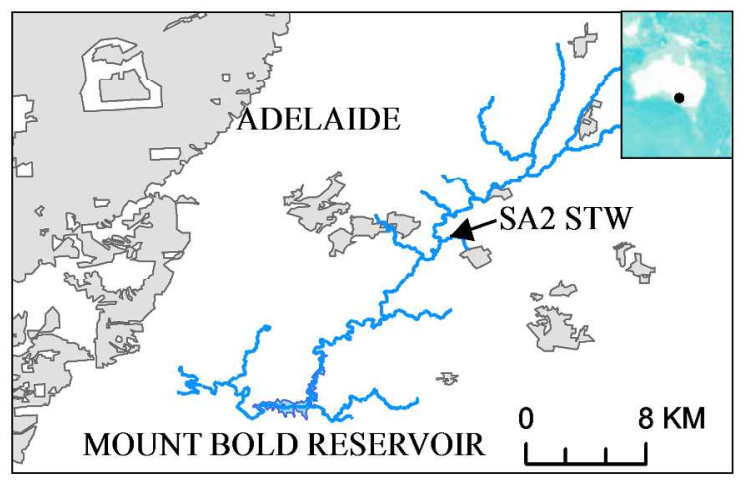

A
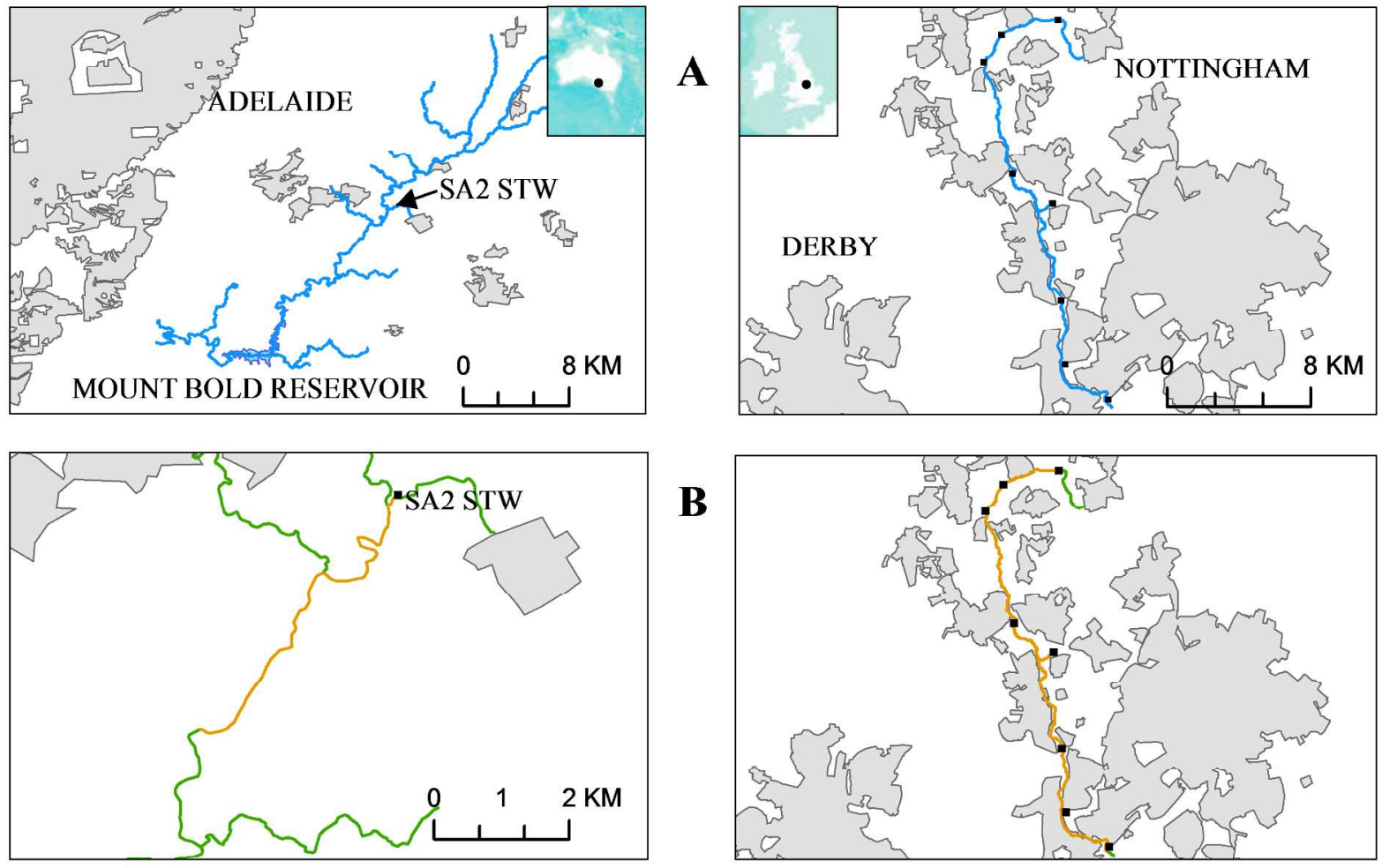

B
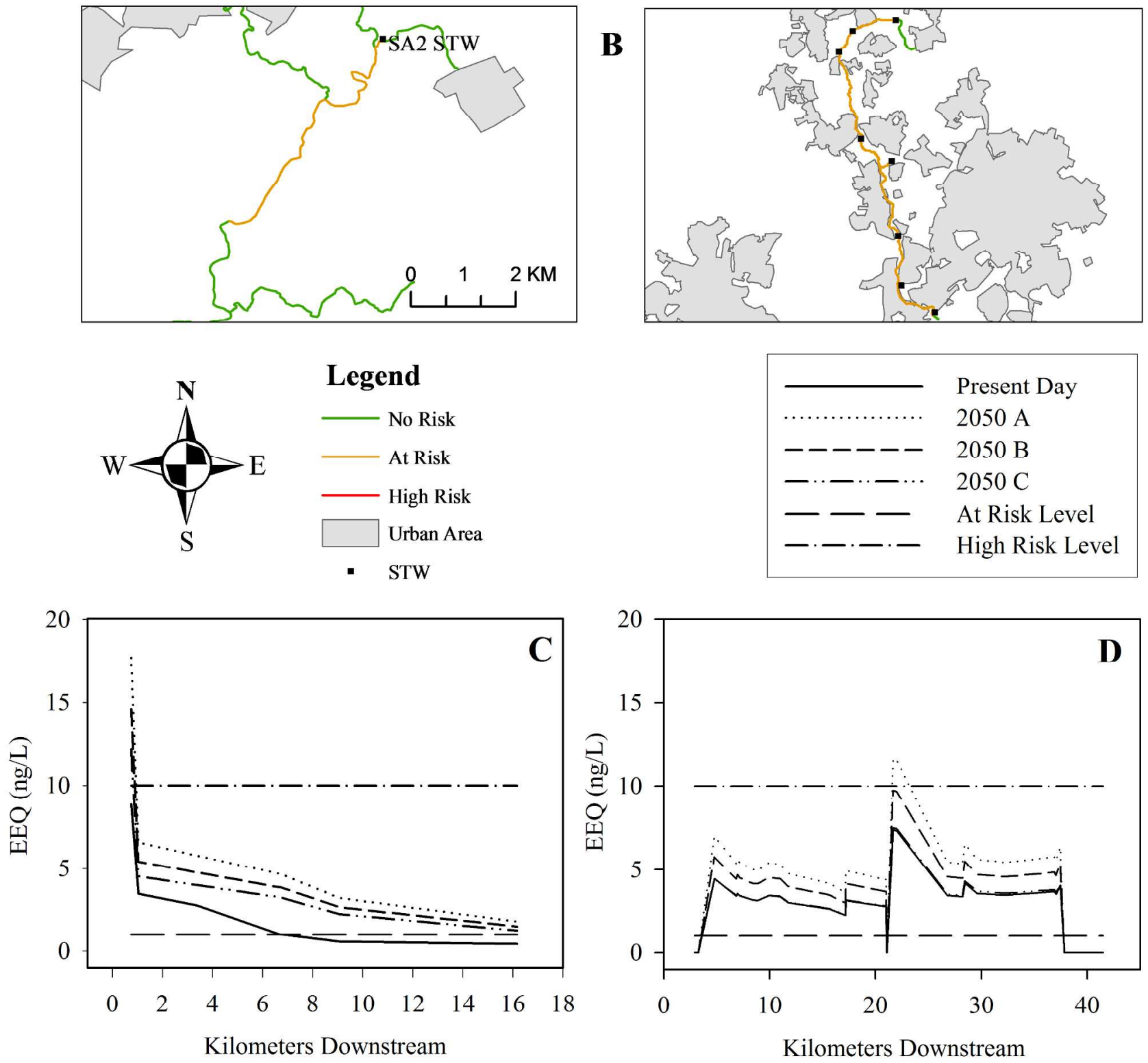

51338

52

53339

54

56 340 Figure 3. Maps showing: (A) The location of the Onkaparinga River, South Australia (left) and the 57 
categories for each stretch based on the average predicted EEQs (ng/L) for the present day on the Onkaparinga (left) and the Erewash (right);. Graphs showing the average predicted EEQs along the

Onkaparinga River downstream of the SA2 STW (C) and the River Erewash downstream from the source (D) in the present day and under the three future population projections, high (2050A), principal (2050B) and low (2050C), with river flows reduced for medium range climate change scenarios. Risk levels are also indicated. A color version is available online at pubs.acs.org.

\section{Scenarios for Concentrations of Steroid Estrogens in 2050}

Effluent concentrations: In both countries three population projections representative of 2050 , including high (A), principal/medium (B) and low (C) projections, were used to determine how the change in human population size (Figure S2, Table S5) and composition (Table S3) affected modeled estrogen concentrations. Interestingly the population composition had a small impact on the per capita load. A small increase occurred under the high projection and a small decrease occurred under the principle and low projections (Figure S3, Table S4) as a result of changes in the proportions of high estrogen producing menstrual females and pregnant females relative to low estrogen producing menopausal females. Population growth had a much greater impact, resulting in an increase in the total estrogen load arriving at the STW (Figure S4) and an increase in their subsequent concentrations in effluents to be discharged into the environment (Figure 4, Table S7). The exception to this was the UK projection $\mathrm{C}$, where effluent concentrations reduced since the increase in population was not sufficient to compensate for the lower per capita load. The worst case scenario was observed with the high population projections, where effluent concentrations almost doubled by 2050 under the Australian projection A. 


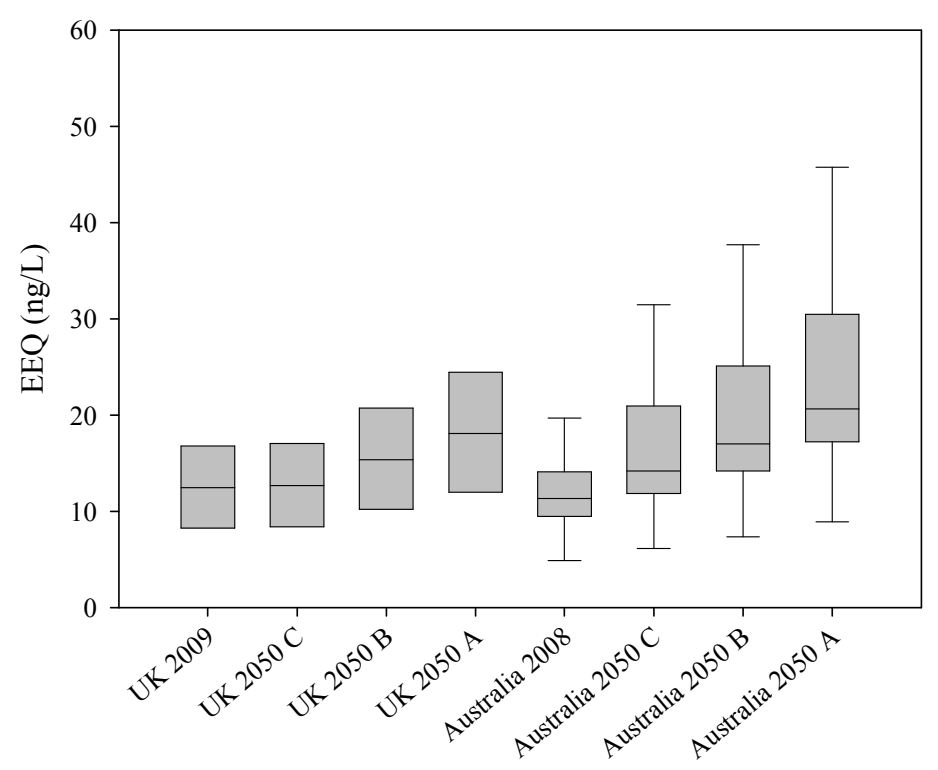

Figure 4. The predicted EEQs of effluents in the UK and South Australia under present day and future projections assuming no change in DWF at the STWs. Boxes represent the median (solid line) with 5th and $95^{\text {th }}$ percentiles (UK) and $25^{\text {th }}$ and $75^{\text {th }}$ percentiles (South Australia). Error bars in South Australian boxes extend to the $5^{\text {th }}$ and $95^{\text {th }}$ percentiles.

River Concentrations: The river models were modified for medium range climate scenarios with reduced flow and used in conjunction with population projections and future estrogen loads to determine how river concentrations may change by 2050 (Figure 3). On the River Erewash, decreased dilution and increased estrogen input in effluent under projections A and B caused increases in the average EEQ on impacted stretches from 3.7 (2.3-7.4) $\mathrm{ng} / \mathrm{L}$ to 5.9 (3.6-11.6) and 4.9 (3-9.7) $\mathrm{ng} / \mathrm{L}$ respectively. In addition, two stretches became "high risk" areas in projection A (Table S8). However, in projection C the increase was smaller with an average EEQ on impacted stretches of $3.8(2.3-7.5) \mathrm{ng} / \mathrm{L}$ due to the reduced input of steroid estrogens from the STWs. An increase in average EEQ was also predicted $52^{378}$ 53 54379 between the SA2 discharge and the Mount Bold reservoir on the Onkaparinga River under all 55 60 
considered "at risk" increased under all three projections to include the entire $16 \mathrm{~km}$ modeled stretch upstream of the reservoir, whilst in projections $\mathrm{A}$ and $\mathrm{B}$ the stretch immediately downstream of SA2 became "high risk". However, it is important to note that additional variables exist in the prediction of estrogen concentrations in the future. For example, measures to conserve water may further reduce dilution of estrogens arriving at STWs, whilst increasing anthropogenic control of river flow and the use of recycled wastewater could result in additional changes to their dilution in rivers. Furthermore, an increasing occurrence of extreme weather events could cause greater changes in flow which could have more dramatic implications for estrogen concentrations than our model suggests. Indeed, variation in flow and dilution may be a much greater driver than population change alone, causing increases or decreases in concentrations that may differ from our model, depending on water availability. Since a better understanding of the drivers that cause at risk areas has been called for ${ }^{29}$, these scenarios may provide interesting subjects for more detailed assessment in the future.

Mitigation to combat rising estrogen concentrations may be achieved with increased removal efficiency at STWs with improved uptake of modern treatment technologies, many of which are already used for treating drinking water and recycled wastewater. This has already been demonstrated in the $\mathrm{UK}^{24,44,66}$ and similar results have been found in Australia ${ }^{68,69}$. Indeed, in Western Australia the induction of the estrogenic biomarker vitellogenin was found in male fish downstream of a secondary treated rural effluent but not downstream of tertiary treatment ${ }^{68}$. However, a number of studies have also detected steroid estrogen concentrations which exceed the PNECs upstream of STWs, demonstrating the importance of considering multiple origins of environmental steroid estrogens ${ }^{3,60,68}$, such as agricultural runoff ${ }^{70}$ as well as sewage effluent. In addition, other chemicals with the potential to cause feminizing effects in wildlife, such as the nonylphenol ethoxylates, which have been restricted under EU legislation, are still in use in Australia and have been detected in surface water ${ }^{60}$. 
This study demonstrates the first use of predictive effluent and river modeling of steroid estrogens in South Australia as an effective tool for estimating concentrations and predicting the presence of "at risk" areas. The results suggest that effluents discharged in South Australia could cause concentrations of steroid estrogens in rivers to exceed the $1 \mathrm{ng} / \mathrm{L}$ EEQ PNEC, implying that there is a risk of endocrine disruptive effects occurring in wild fish. Evidence of feminization of non-native fish has already been observed in effluent contaminated areas ${ }^{68,71,72}$, whilst native species have been shown to be susceptible to steroid estrogens under laboratory exposure ${ }^{73,74}$. As a result, further investigation is warranted to determine how susceptible Australian species are to estrogens from all sources, particularly from effluents derived from different levels of sewage treatment, which will allow Australian PNECs to be derived that accurately reflect the risks and mitigation required to protect Australian biota. In the absence mitigation strategies we could anticipate an increase in estrogen concentrations in rivers in both the UK and Australia by 2050 as a result of the growing populations coupled with reductions in river flow through changing climate. Moreover the magnitude of this change may increase further with continued reduction in flow and population rise by 2100 and beyond. This suggests that endocrine disruption in wild fish may be a long-term management issue for which effective investment in preemptive mitigation today may pay off in the future.

\section{ASSOCIATED CONTENT}

\section{Supporting Information Available}

The supplementary data section includes: a simple worked example of effluent modeling at a South Australian STW; Tables of the parameters for each STW; half-lives for the steroid estrogens used in the Source Catchments model; cohort percentages from census data for the present day and future projections; per capita loads for the present day and future projections; fold change in population between 2011 and 2051; the measured and modeled data range of estrogens from UK and Australian STW effluents; predicted effluent EEQs for the present day and 2050 scenarios; risk categories of river 
stretches for the present day and future projections; Graphs of the predicted effluent concentrations of the steroid estrogens in UK and Australian effluents; population change; per capita load of estrogens and total estrogen load arriving at a STW up to 2050 for all population scenarios. This material is available free of charge via the Internet at http://pubs.acs.org.

\section{AUTHOR INFORMATION}

\section{Corresponding Author}

*Christopher Green.

Institute for the Environment, Brunel University, Uxbridge, Middlesex, UB8 3PH, UK.

Tel. $+44(0) 1895266267$

Fax. $+44(0) 1895269761$

Email: christopher.green@brunel.ac.uk

\section{Author Contributions}

All authors have given approval to the final version of the manuscript.

\section{Funding Sources}

Funding was provided by the Commonwealth Scientific and Industrial Research Organization (CSIRO) and Brunel University

\section{Notes}

The authors declare no competing financial interest. The data provided courtesy of Severn Trent Water Ltd are on the basis that they are for the sole use in connection with "An integrated approach to assess safety of treated wastewaters as environmental flows in the Australian riverine environment: The UK-Australia collaboration" and are not to be used for any other purpose. Any views expressed are those of the author/s and do not necessarily represent those of Severn Trent Water Ltd. The copyright of the data remains with Severn Trent Water Ltd. 


\section{ABBREVIATIONS}

ABS, Australian Bureau of Statistics; ASP, Activated Sludge Process, DWF, Dry Weather Flow; E1, estrone; E2, 17 $\beta$-estradiol; EE2, 17 $\alpha$-Ethinylestradiol; EEQ, E2 equivalent concentration; GAC, Granular Activated Carbon; HRT, Hormone Replacement Therapy; LC-MS/MS, Liquid Chromatography-tandem Mass Spectroscopy; LF2000-WQX, Low Flows 2000 Water Quality eXtention model; ONS, Office of National Statistics; PNEC, Predicted No Effect Concentration; STW, sewage treatment works, UKCP09, UK Climate Projections 2009.

\section{REFERENCES}

1. Kolpin, D. W.; Furlong, E. T.; Meyer, M. T.; Thurman, E. M.; Zaugg, S. D.; Barber, L. B.; Buxton, H. T. Pharmaceuticals, hormones, and other organic wastewater contaminants in U.S. streams, 19992000: a national reconnaissance. Environ. Sci. Technol. 2002, 36, 1202-1211.

2. Sumpter, J. P. Endocrine Disrupters in the Aquatic Environment: An Overview. Acta Hydrochim. Hydrobiol. 2005, 33, 9-16. 
3. Williams, M.; Woods, M.; Kumar, A.; Ying, G.; Shareef, A.; Karkkainen, M.; Kookana, R. Endocrine disrupting chemicals in the Australian riverine environment: a pilot study on oestrogenic compounds. 2007, Land and Water Australia, Canberra, Australia

4. Williams, R. J.; Keller, V. D. J.; Johnson, A. C.; Young, A. R.; Holmes, M. G. R.; Wells, C.; GrossSorokin, M.; Benstead, R. A national risk assessment for intersex in fish arising from steroid estrogens. Environ. Toxicol. Chem. 2009, 28, 220-230.

5. Ternes, T. A.; Kreckel, P.; Mueller, J. Behaviour and occurrence of estrogens in municipal sewage treatment plants - II. Aerobic batch experiments with activated sludge. Sci. Total Environ. 1999, 225, 91-99.

6. Jobling, S.; Nolan, M.; Tyler, C. R.; Brighty, G.; Sumpter, J. P. Widespread sexual disruption in wild fish. Environ. Sci. Technol. 1998, 32, 2498-2506.

7. Tetreault, G. R.; Bennett, C. J.; Cheng, C.; Servos, M. R.; McMaster, M. E. Reproductive and histopathological effects in wild fish inhabiting an effluent-dominated stream, Wascana Creek, SK, Canada. Aquat. Toxicol. 2012, 110-111, 149-161.

8. Swayne, M. D.; Boone, G. H.; Bauer, D.; Lee, J. S. Wastewater in recieving waters at water supply abstraction points. 1980, EPA-600/2-80-044.

9. Desbrow, C.; Routledge, E. J.; Brighty, G. C.; Sumpter, J. P.; Waldock, M. Identification of estrogenic chemicals in STW effluent. 1. Chemical fractionation and in vitro biological screening. Environ. Sci. Technol. 1998, 32, 1549-1558.

10. Routledge, E. J.; Sheahan, D.; Desbrow, C.; Brighty, G. C.; Waldock, M.; Sumpter, J. P. Identification of estrogenic chemicals in STW effluent. 2. In vivo responses in trout and roach. Environ. Sci. Technol. 1998, 32, 1559-1565. 
11. Jobling, S.; Williams, R.; Johnson, A.; Taylor, A.; Gross-Sorokin, M.; Nolan, M.; Tyler, C. R.;

van Aerle, R.; Santos, E.; Brighty, G. Predicted exposures to steroid estrogens in U.K. rivers correlate with widespread sexual disruption in wild fish populations. Environ. Health Perspect. 2006, 114 Suppl

$\begin{array}{lll}5 & 503 & \text { with wide } \\ 6 & \\ 7 & 504 & \\ 8 & & \\ 9 & \end{array}$

12. Tyler, C. R.; Jobling, S.; Sumpter, J. P. Endocrine disruption in wildlife: A critical review of the evidence. Crit. Rev. Toxicol. 1998, 28, 319-361.

13. Metcalfe, C. D.; Metcalfe, T. L.; Kiparissis, Y.; Koenig, B. G.; Khan, C.; Hughes, R. J.; Croley, T. R.; March, R. E.; Potter, T. Estrogenic potency of chemicals detected in sewage treatment plant effluents as determined by in vivo assays with Japanese medaka (Oryzias latipes). Environ. Sci. Technol. 2001, 20, 297-308.

14. Lange, A.; Paull, G. C.; Coe, T. S.; Katsu, Y.; Urushitani, H.; Iguchi, T.; Tyler, C. R. Sexual reprogramming and estrogenic sensitization in wild fish exposed to ethinylestradiol. Environ. Sci. Technol. 2009, 43, 1219-1225.

15. Jafri, S. I. H.; Ensor, D. M. Occurrence of an intersex condition in the roach (Rutilus rutilus). J. Fish Biol. 1979, 14, 547-549.

16. Bjerregaard, L.; Madsen, A.; Korsgaard, B.; Bjerregaard, P. Gonad histology and vitellogenin concentrations in brown trout (Salmo trutta) from Danish streams impacted by sewage effluent. Ecotoxicology 2006, 15, 315-327.

17. Vajda, A. M.; Barber, L. B.; Gray, J. L.; Lopez, E. M.; Woodling, J. D.; Norris, D. O. Reproductive disruption in fish downstream from an estrogenic wastewater effluent. Environ. Sci. Technol. 2008, 42, 3407-3414. 
21 22530 23

29 30533 31 32534 33 34 35535 36 37 $38^{536}$ 39 40537

18. Harris, C. A.; Hamilton, P. B.; Runnalls, T. J.; Vinciotti, V.; Henshaw, A.; Hodgson, D.; Coe, T.

S.; Jobling, S.; Tyler, C. R.; Sumpter, J. P. The consequences of feminization in breeding groups of wild fish. Environ. Health Perspect. 2011, 119, 306-311.

19. Kidd, K. A.; Blanchfield, P. J.; Mills, K. H.; Palace, V. P.; Evans, R. E.; Lazorchak, J. M.; Flick, R. W. Collapse of a fish population after exposure to a synthetic estrogen. Proc. Natl. Acad. Sci. U. S. A. 2007, 104, 8897-8901.

20. Owen, R.; Jobling, S. Environmental science: The hidden costs of flexible fertility. Nature 2012, $485,441-441$.

21. Johnson, A. C.; Belfroid, A.; Di Corcia, A. D. Estimating steroid oestrogen inputs into activated sludge treatment works and observations on their removal from the effluent. Sci. Total Environ. 2000, $256,163-173$.

22. Schowanek, D.; Webb, S. Exposure simulation for pharmaceuticals in European surface waters with GREAT-ER. Toxicol. Lett. 2002, 131, 39-50.

23. Johnson, A. C.; Williams, R. J. A model to estimate influent and effluent concentrations of estradiol, estrone, and ethinylestradiol at sewage treatment works. Environ. Sci. Technol. 2004, 38, $3649-3658$.

24. Johnson, A. C.; Williams, R. J.; Simpson, P.; Kanda, R. What difference might sewage treatment performance make to endocrine disruption in rivers? Environ. Pollut. 2007, 147, 194-202.

25. Sumpter, J. P.; Johnson, A. C.; Williams, R. J.; Kortenkamp, A.; Scholze, M. Modeling effects of mixtures of endocrine disrupting chemicals at the river catchment scale. Environ. Sci. Technol. 2006, $40,5478-5489$. 
26. Anderson, P. D.; Johnson, A. C.; Pfeiffer, D.; Caldwell, D. J.; Hannah, R.; Mastrocco, F.; Sumpter, J. P.; Williams, R. J. Endocrine disruption due to estrogens derived from humans predicted to be low in the majority of U.S. surface waters. Environ. Toxicol. Chem. 2012, 31, 1407-1415.

27. Johnson, A. C.; Yoshitani, J.; Tanaka, H.; Suzuki, Y. Predicting national exposure to a point source chemical: Japan and endocrine disruption as an example. Environ. Sci. Technol. 2011, 45, 10281033.

28. Bertin, A.; Inostroza, P. A.; Quinones, R. A. A theoretical estimation of the concentration of steroid estrogens in effluents released from municipal sewage treatment plants into aquatic ecosystems of central-southern Chile. Sci. Total Environ. 2009, 407, 4965-4971.

29. Boxall, A. B.; Rudd, M. A.; Brooks, B. W.; Caldwell, D. J.; Choi, K.; Hickmann, S.; Innes, E.; Ostapyk, K.; Staveley, J. P.; Verslycke, T.; Ankley, G. T.; Beazley, K. F.; Belanger, S. E.; Berninger, J. P.; Carriquiriborde, P.; Coors, A.; Deleo, P. C.; Dyer, S. D.; Ericson, J. F.; Gagne, F.; Giesy, J. P.; Gouin, T.; Hallstrom, L.; Karlsson, M. V.; Larsson, D. G.; Lazorchak, J. M.; Mastrocco, F.; McLaughlin, A.; McMaster, M. E.; Meyerhoff, R. D.; Moore, R.; Parrott, J. L.; Snape, J. R.; MurraySmith, R.; Servos, M. R.; Sibley, P. K.; Straub, J. O.; Szabo, N. D.; Topp, E.; Tetreault, G. R.; Trudeau, V. L.; Van Der Kraak, G. Pharmaceuticals and personal care products in the environment: what are the big questions? Environ. Health Perspect. 2012, 120, 1221-1229.

30. United Nations. World Population Prospects: The 2010 Revision, Highlights and Advance Tables. 2011, Working Paper No. ESA/P/WP.220.

31. Bates, B. C.; Kundzewicz, Z. W.; Wu, S.; Palutikof, J. P. Climate change and water. Technical paper of the Intergovernmental Panel on Climate Change. 2008.

32. Environment Agency. Water resources in England and Wales - current state and future pressures. 2008, GEHO1208BPAS-E-E. 
566

2 3567

4

5 6568 7

33. HM Government and DEFRA Future Water. The Government's water strategy for England. 2008,

PB13562.

34. National Water Commission. Assessing water stress in Australian catchments and aquifers. 2012, NWC, Canberra, Australia.

35. Government of South Australia. Water for good: A plan to ensure our water future to 2050. 2010, Office for Water Security, Adelaide, Australia.

36. MacLennan, A. H.; Gill, T. K.; Broadbent, J. L.; Taylor, A. W. Continuing decline in hormone therapy use: population trends over 17 years. Climacteric 2009, 12, 122-130.

37. Watson, J.; Wise, L.; Green, J. Prescribing of hormone therapy for menopause, tibolone, and bisphosphonates in women in the UK between 1991 and 2005. Eur. J. Clin. Pharmacol. 2007, 63, 843-849.

38. The NHS Information Centre, Prescribing Support Unit. Prescriptions Cost Analysis: England 2009. 2010. www.ic.nhs.uk.

39. Welsh Assembly Government. Prescriptions dispensed in the community in Wales, 2000 to 2009 and Prescription Cost Analysis (PCA) Data. 2010, SDR 49/2010.

40. Australian Government Department for Health and Aging. Australian Statistics on Medicines 2008. 2009, ISBN: 978-1-74241-110-1.

41. Runnalls, T. J.; Margiotta-Casaluci, L.; Kugathas, S.; Sumpter, J. P. Pharmaceuticals in the aquatic environment: steroids and anti-steroids as high priorities for research. J. Hum. Ecol. Risk Assess 2010, $16,1318-1338$. 
42. Williams, R. J.; Johnson, A. C.; Keller, V. D. J.; Wells, C.; Holmes, M. G. R.; Young, A. R.

Catchment risk assessment of steroid oestrogens from sewage treatment works. 2008, Science Report SC030275/SR3.

43. Johnson, A. C.; Ternes, T.; Williams, R. J.; Sumpter, J. P. Assessing the concentrations of polar organic microcontaminants from point sources in the aquatic environment: measure or model? Environ. Sci. Technol. 2008, 42, 5390-5399.

44. Baynes, A.; Green, C.; Nicol, E.; Beresford, N.; Kanda, R.; Henshaw, A.; Churchley, J.; Jobling, S. Additional treatment of wastewater reduces endocrine disruption in wild fish -- A comparative study of tertiary and advanced treatments. Environ. Sci. Technol. 2012, 46, 5565-5573.

45. Kanda, R.; Churchley, J. Removal of endocrine disrupting compounds during conventional wastewater treatment. Environ. Technol. 2008, 29, 315-323.

46. Jürgens, M. D.; Holthaus, K. I. E.; Johnson, A. C.; Smith, J. J. L.; Hetheridge, M.; Williams, R. J. The potential for estradiol and ethinylestradiol degradation in English rivers. Environ. Toxicol. Chem. 2002, 21, 480-488.

47. Holthaus, K. I. E.; Johnson, A. C.; Jürgens, M. D.; Williams, R. J.; Smith, J. J. L.; Carter, J. E. The potential for estradiol and ethinylestradiol to sorb to suspended and bed sediments in some English rivers. Environ. Toxicol. Chem. 2002, 21, 2526-2535.

48. eWater Cooperative Research Centre. Source Catchments User Guide. 2010, ISBN 978-1-92154329-6.

49. eWater Cooperative Research Centre. Source Catchments Scientific Reference Guide. 2010, ISBN 978-1-921543-30-2. 
50. Young, W. F.; Whitehouse, P.; Johnson, I.; Sorokin, N. Proposed Predicted-No-Effect-

21

Concentrations (PNECs) for natural and synthetic steroid oestrogens in surface waters. 2004,

Environment Agency R\&D Technical Report P2-T04/1.

51. Williams, R. J.; Churchley, J. H.; Kanda, R.; Johnson, A. C. Comparing predicted against measured steroid estrogen concentrations and the associated risk in two United Kingdom river catchments. Environ. Toxicol. Chem. 2012, 892-898.

52. Office for National Statistics National Population Projections, 2010-Based Projections. http://www.ons.gov.uk/ons/publications/re-reference-tables.html?edition=tcm\%3A77-229866.

53. Australian Bureau of Statistics 3222.0 - Population Projections, Australia, 2006 to 2101. http://www.abs.gov.au/Ausstats/abs@.nsf/mf/3222.0.

54. Prudhomme, C.; Young, A.; Watts, G.; Haxton, T.; Crooks, S.; Williamson, J.; Davies, H.; Dadson, S.; Allen, S. The drying up of Britain? A national estimate of changes in seasonal river flows from 11 Regional Climate Model simulations. Hydrol. Process. 2012, 26, 1115-1118.

55. Beare, S.; Heaney, A. In In Climate change and water resources in the Murrary Darling Basin, Australia: Impacts and possible adaptation. 2002, World Congress on Environmental and Resource Economists; World Congress on Environmental and Resource Economists: Monterey, California.

56. Allinson, M.; Shiraishi, F.; Salzman, S.; Allinson, G. In vitro and immunological assessment of the estrogenic activity and concentrations of $17 \beta$-estradiol, estrone, and ethinyl estradiol in treated effluent from 45 wastewater treatment plants in Victoria, Australia. Arch. Environ. Contam. Toxicol. 2010, $58,576-586$.

57. Johnson, I.; Hetheridge, M.; Tyler, C. R. Assessment of (anti-) oestrogenic and (anti-) androgenic activities of final effluents from sewage treatment works. 2007, Science Report SC020118/SR. 
58. Mispagel, C.; Allinson, G.; Allinson, M.; Shiraishi, F.; Nishikawa, M.; Moore, M. Observations on the estrogenic activity and concentration of $17 \beta$-estradiol in the discharges of 12 wastewater treatment plants in Southern Australia. Arch. Environ. Contam. Toxicol. 2009, 56, 631-637.

59. Ying, G.; Kookana, R. S.; Kumar, A. Fate of estrogens and xenoestrogens in four sewage treatment plants with different technologies. Environ. Toxicol. Chem. 2008, 27, 87-94.

60. Ying, G.; Kookana, R. S.; Kumar, A.; Mortimer, M. Occurrence and implications of estrogens and xenoestrogens in sewage effluents and receiving waters from South East Queensland. Sci. Total Environ. 2009, 407, 5147-5155.

61. Leusch, F. D. L.; Chapman, H. F.; van den Heuvel, M. R.; Tan, B. L. L.; Gooneratne, S. R.; Tremblay, L. A. Bioassay-derived androgenic and estrogenic activity in municipal sewage in Australia and New Zealand. Ecotoxicol. Environ. Saf. 2006, 65, 403-411.

62. Tan, B. L. L.; Hawker, D. W.; Müller, J. F.; Leusch, F. D. L.; Tremblay, L. A.; Chapman, H. F. Comprehensive study of endocrine disrupting compounds using grab and passive sampling at selected wastewater treatment plants in South East Queensland, Australia. Environ. Int. 2007, 33, 654-669.

63. Braga, O.; Smythe, G. A.; Schäfer, A. I.; Feitz, A. J. Fate of steroid estrogens in Australian inland and coastal wastewater treatment plants. Environ. Sci. Technol. 2005, 39, 3351-3358.

64. Li, Z.; Wang, S.; Alice Lee, N.; Allan, R. D.; Kennedy, I. R. Development of a solid-phase extraction-enzyme-linked immunosorbent assay method for the determination of estrone in water. Anal. Chim. Acta 2004, 503, 171-177.

65. Vieno, N. M.; Tuhkanen, T.; Kronberg, L. Seasonal Variation in the Occurrence of Pharmaceuticals in Effluents from a Sewage Treatment Plant and in the Recipient Water. Environ. Sci. Technol. 2005, 39, 8220-8226. 
66. Butwell, A. J.; Harman, M.; Johnson, I.; Rockett, L.; Silvil, D. Assessment of the performance of wastewater treatment works in removing oestrogenic substances. 2010, UK Water Industry Research Report 10/TX/04/17.

67. Ying, G.; Kookana, R. S.; Ru, Y. Occurrence and fate of hormone steroids in the environment. Environ. Int. 2002, 28, 545-551.

68. Reitsema, T.; Nice, H. E.; Leusch, F. D. L.; Quayle, P.; Chapman, H. F.; Khan, S. J.; Trinh, T.; Coleman, H.; Rawson, C.; Gagnon, M. M.; Blair, P. Development of an 'ecotoxicity toolbox' to characterise water quality for recycling. 2010, Report no. 36. Water Science Technical Series, Department of Water, Western Australia.

69. Kumar, A.; Williams, M.; Woods, M.; Kookana, R.; Barber, L.; Vajda, A.; Doan, H.; Gregg, A.; Gonzago, D.; Bain, P. Treated effluent in the aquatic environment: impact assessment of endocrine disrupting chemicals. 2012, CSIRO: Water for a Healthy Country National Research Flagship.

70. Matthiessen, P.; Arnold, D.; Johnson, A. C.; Pepper, T. J.; Pottinger, T. G.; Pulman, K. G. T. Contamination of headwater streams in the United Kingdom by oestrogenic hormones from livestock farms. Sci. Total Environ. 2006, 367, 616-630.

71. Batty, J.; Lim, R. Morphological and reproductive characteristics of male mosquitofish (Gambusia affinis holbrooki) inhabiting sewage-contaminated waters in New South Wales, Australia. Arch. Environ. Contam. Toxicol. 1999, 36, 301-307.

72. Rawson, C. A.; Lim, R. P.; Warne, M. S. J. Skeletal morphology and maturation of male Gambusia holbrooki exposed to sewage treatment plant effluent. Ecotoxicol. Environ. Saf. 2008, 70, 453-461. 
${ }_{1} 672$ 73. Codi King, S.; Hassell, K.; Nugegoda, D.; Kristiansen, S. I. The assessment of vitellogenin as a ${ }_{3}^{2} 673$ biomarker of exposure to estrogenic compounds in two Australian perciformes. Mar. Environ. Res. 4 5674 2008, 66, 116-118.

6

7

8675 ${ }_{11}^{10} 676$ 12 13 14677 15

16

17

18

19

20

21

22

23

24

25

26

27

28

29

30

31

32

33

34

35

36

37

38

39

40

41

42

43

44

45

46

47

48

49

50

51

52

53

54

55

56

57

58

59

60

74. Woods, M.; Kumar, A. Vitellogenin induction by $17 \beta$-estradiol and $17 \alpha$-ethynylestradiol in male Murray rainbowfish (Melanotaenia fluviatilis). Environ. Toxicol. Chem. 2011, 30, 2620-2627. 